\title{
Gravity modelling of the lower crust in Sardinia (Italy)
}

\author{
Maria Teresa Carrozzo $\left({ }^{1}\right)$, Roberto Balia $\left({ }^{2}\right)$, Mariano Loddo $\left({ }^{3}\right)$, Dario Luzio $\left({ }^{4}\right)$, Carlo Margiotta $\left({ }^{1}\right)$, \\ Tatiana Quarta $\left({ }^{1}\right)$ and Renato Trudu $\left({ }^{2}\right)$ \\ $\left(^{2}\right)$ Istituto di Giacimenti Minerari, Geofisica e Scienze Geologiche, Università di Cagliari, Italy \\ ${ }^{3}$ ) Dipartimento di Geologia e Geofisica, Università di Bari, Italy \\ $\left({ }^{4}\right)$ Istituto di Geofisica Mineraria, Università di Palermo, Italy
}

\begin{abstract}
In this paper an example is given of an application of statistical techniques to the Bouguer anomalies analysis in order to design a simple crustal model using few a priori assumptions. All gravity measurements carried out in Sardinia have been collected and processed. The Bouguer anomalies have been calculated according to local density estimates. Spectral analysis of the Bouguer anomalies has been carried out along selected profiles in order to estimate the mean depth of the Moho discontinuity and that of an infracrustal discontinuity. The use of this technique inferred the presence of a discontinuity at a mean depth of $\sim 28 \mathrm{~km}$, interpreted as Moho and
the likely presence of an infracrustal discontinuity at a mean depth of $\sim 18 \mathrm{~km}$, interpreted as the upper-lower crust transition. In order to roughly reconstruct the shape of these interfaces, $2 \mathrm{D}$ inversion techniques were applied to the large wavelength components of the Bouguer anomalies, relative to profiles oriented along the E-W direction, extracted from low-pass filtered Bouguer anomaly maps. The density model obtained is compatible with some velocity models achieved from the interpretation of the seismic refraction profiles carried out within the European Geotraverse project.
\end{abstract}

Key words gravity - seismic - spectral analysis filtering - modelling .

\section{Introduction}

Most of the contributions regarding the definition of the crustal structures generally are based on the synthesis of information coming from a co-operative interpretation of the geophysical data and from geological constraints. It is well known that in such a way it is theoretically possible to reduce the non-uniqueness of the inverse problem with respect to that related to the inversion of the single kinds of data. Therefore, the application of sequential

Mailing address: Dr. Tatiana Quarta, Dipartimento di Scienza dei Materiali, Università di Lecce, Via Arnesano, 73100 Lecce, Italy; e-mail: quarta@axpmat.unile.it techniques for the co-operative inversion of the data, could produce the propagation in the final model of a possible distortion introduced in the initial model realized.

In the common crustal modelling procedure Bouguer anomalies are used to test, through a velocity vs. density correlation law (Nafe and Drake, 1957; Birch, 1964), the velocity models relative to the seismic profiles previously investigated, and possibly to sketch in the trends of the seismically spotted structures.

Usually the portions of the velocity model strongly constrained by seismic data are so little spatially extended that, by slight adjustments suitably distributed in the zones, which are least constrained by seismic data, it is possible to design corresponding velocity and density models respectively compatible with seismic and gravimetric data. Finally a use of Bouguer anomalies according to such a scheme does not seem suitable to verify the correctness 
of the correlated dromochrones inversion, especially in complex geological structures.

Sometimes the complexity of seismic data suggests different velocity models, which often can imply geological interpretations contrasting with one another. It is a common experience that Bouguer anomaly inversion has seldom established in statistical terms which of the proposed models is the most suitable.

In this paper an attempt is made to show how a statistical analysis of Bouguer anomalies gives information on the existence of possible irregular density discontinuities surfaces and their mean depth. Such indications obtained only from gravity data, however uncertain, can more efficaciously support the geophysical data interpretation.

The crustal structure of Sardinia has so far been studied mainly by the inversion of the cinematic data belonging to all the DSS profiles carried out in the Sardinian-Corsican area, using 2D models (Guerra (Gruppo Italiano Grandi Profili Sismici), 1981; Biella et al., 1983; Egger et al., 1988).

The models proposed by these authors feature meaningful differences in some parts. The comparison of such models with those obtained in this paper allows a more reliable definition of the deep structure of the Sardinian area.

\section{Structural features of Sardinia}

The geological structure of Sardinia (fig. 1) is made up of at least two main elements (Pala et al., 1982). The Tertiary Sardinian rift, extending from north to south in the western part of the island, with the recent Campidano graben, and the system of horsts in which the outcropping Palaeozoic basement is divided. The fill of the rift is made up of volcanites (especially andesites, ignimbrites and rhyodacites) and by marine and continental deposits of the Oligocene-Miocene. As regards the outcroppings of the basement, the eastern horst, which is apparently homogeneous, compact and continuous, is dominated, in its central-northern part and in the southern tip by Hercynian granites and in the intermediate part by volcanicsedimentary fossiliferous formations of the

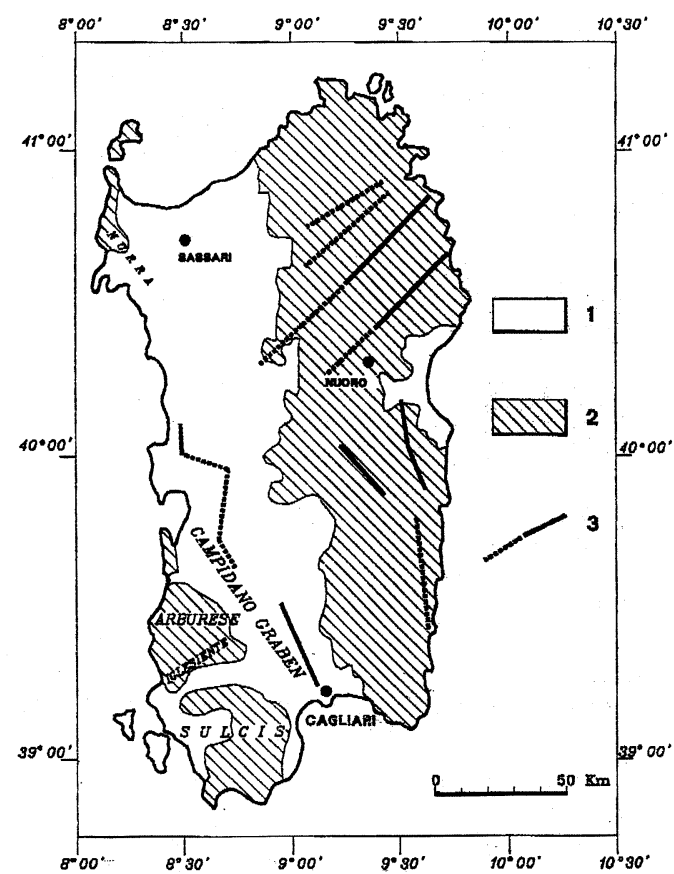

Fig. 1. Structural sketch map of Sardinia. Legend: 1) Oligo-Miocene rift; 2) Paleozoic basement; 3) main faults.

Palaeozoic, often represented by Hercynian green schists. The western horst is dismembered into a series of blocks, the Nurra block, the Iglesiente block and the Sulcis block. The last two are characterized by the presence of the Cambrian in its typical stratigraphic series with metalliferous mineralization, prevalently lead and zinc (Salvadori et al., 1986).

\section{Bouguer anomalies}

The Bouguer anomalies of Sardinia calculated for the edition of the Gravity Map of Italy on the basis of $\sim 3000$ gravity stations (Carrozzo et al., 1981, 1985; Balia et al., 1983) have now been drawn up using an updated set of 5000 data. The reasons these numerous measurements have so far been carried out can be classified into two categories: the study of 
the principal geologic structures of Sardinia by means of regional surveys and the identification of georesources by means of local surveys. All the gravity data regarding Sardinia were collected from various surveys (e.g., Trudu, 1962, 1963; Balia et al., 1983, 1984, 1990, 1991; Pecorini et al., 1988), and were at first checked and made homogeneous by referring them all to the Cagliari station of the Italian First Order Gravity Net (Marson and Morelli, 1978) and as a consequence to the IGSN 71 (Morelli et al., 1974). The stations are irregularly distributed and their density of distribution ranges among the 1-2 per $\mathrm{km}^{2}$ in the areas of greatest mining interest of the Sardinian rift, and the $4-5$ per $100 \mathrm{~km}^{2}$ in the inaccessible mountainous parts of the centre-east and in the surrounding sea (fig. 2). This distribution, however, is generally sufficient for our purposes.

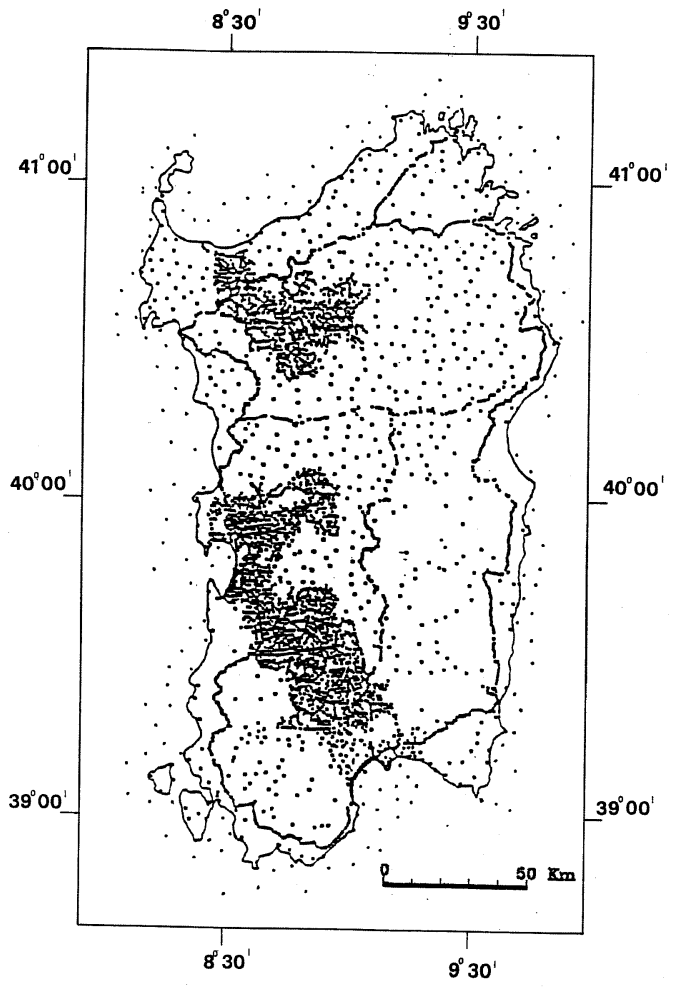

Fig. 2. Position map of the gravity stations.

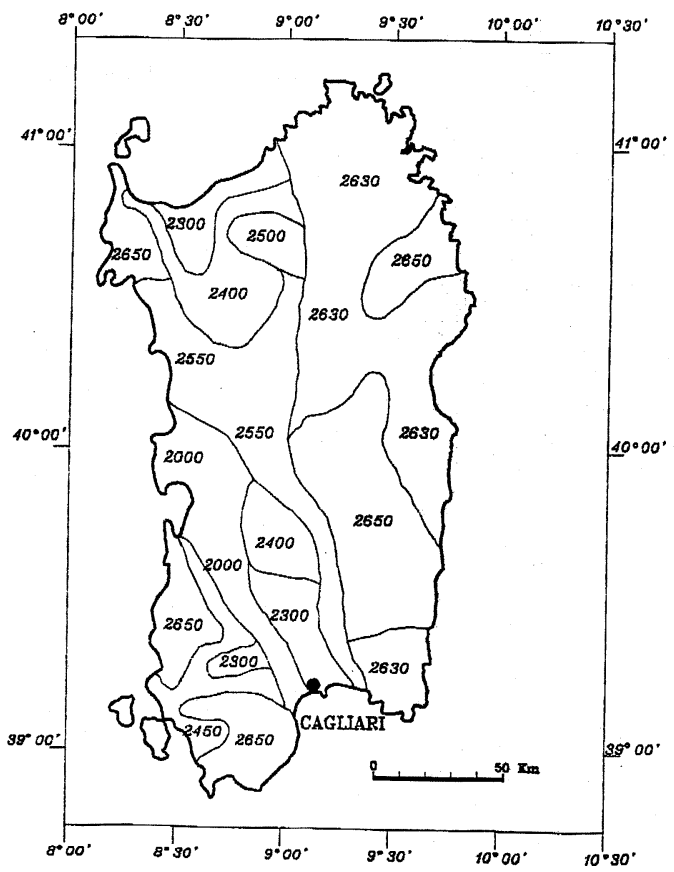

Fig. 3. Map of the statistically determined local mean densities $\left(\mathrm{kg} / \mathrm{m}^{3}\right)$ up to sea level.

To reduce the residual topography effect on the Bouguer anomalies the mean density up to the sea level of the geological formations was estimated. For this reason the existing bibliographic information was used, concerning the density values determined on rock samples taken from the ground or from wells (Vecchia, 1955; Trudu, 1962). On the basis of these values and from geological evidence, a general division of Sardinia into areas could be established, in which the mean rock density should be approximately constant. To attribute the most suitable mean density value to each of these areas, the Bouguer anomalies were calculated for each of their station with different values of the density ranging from 1900 to $3000 \mathrm{~kg} / \mathrm{m}^{3}$, with a step of $100 \mathrm{~kg} / \mathrm{m}^{3}$. For each area the density value was determined which minimizes the correlation coefficients between the Bouguer anomalies and the topography. The topographic heights have been taken from 
the gravity measurements data base (Carrozzo et al., 1985). The statistically determined local mean densities shown in fig. 3 are in good agreement with the geological structures of Sardinia sketched in fig. 1. The calculated Bouguer anomaly values were interpolated at the vertices of a regular grid covering the entire area involved in the study. The dimensions of the grid are as follows: $171 \mathrm{~km}$ in the EW direction and $305 \mathrm{~km}$ in the NS direction; the side of the square grid is $1 \mathrm{~km}$ long. The map of the Bouguer anomalies, calculated for local mean densities, is shown in fig. 4 . The step between contour lines is $50 \mathrm{gu}$. In order to verify the effect of calculating the anomalies for the local densities, a map of differences between these anomalies and those calculated for the

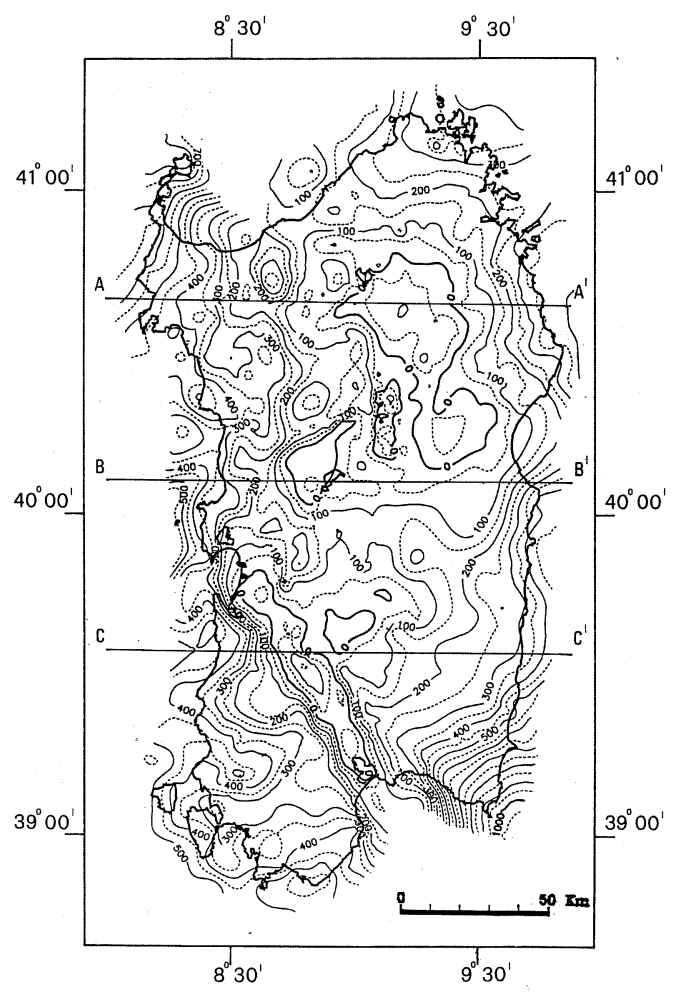

Fig. 4. Bouguer anomalies calculated by local mean densities (contour interval $50 \mathrm{gu}$ ) and position map of the three analysed profiles. constant densities of $2400 \mathrm{~kg} / \mathrm{m}^{3}$ was represented (fig. 5). This map shows that in the Bouguer anomalies calculated with constant densities, effects of the surface structures are present even on the components with mediumlarge wavelength. These kinds of signals could affect the determination of the trends also of the deep discontinuities. The contour lines in fig. 4 show a main trend parallel to the coastline and in the southern part of the island they clearly outline the structure of the Campidano graben. In the northern part they seem to show a certain kind of structural continuity between the Corsican and Sardinian blocks. The anomaly values are positive on most of the island and tend to increase from the centre towards the coastline. This trend determines an

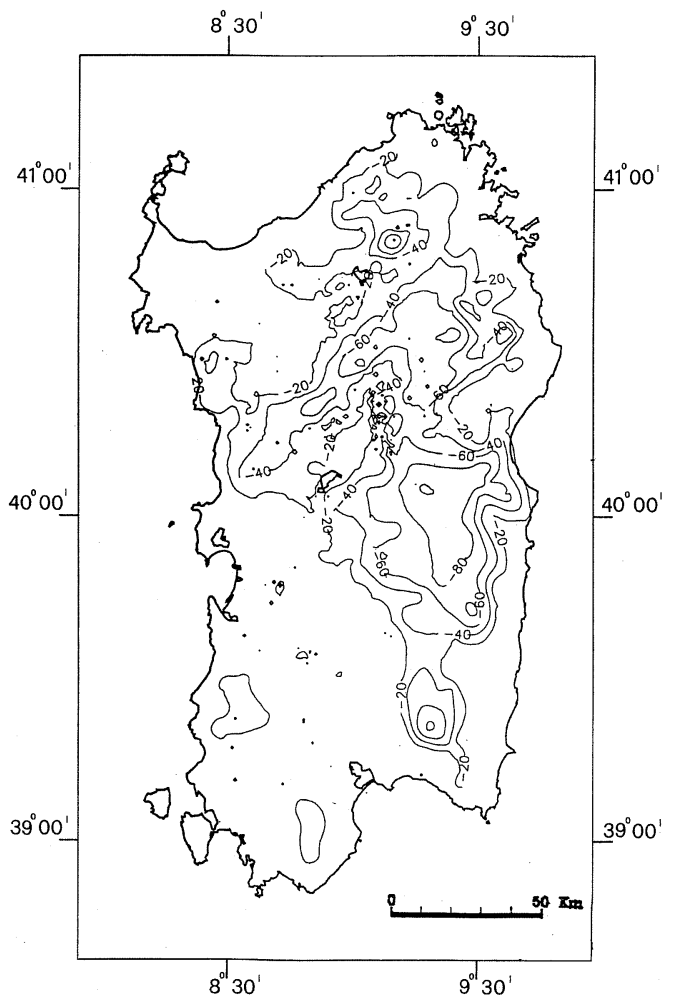

Fig. 5. The differences between the Bouguer anomalies calculated by local mean densities and those by $2400 \mathrm{~kg} / \mathrm{m}^{3}$ densities. 
extended regional minimum, centred in the north-eastern granitic area. The distribution of the gravity values is clearly more regular in the eastern sector, which is dominated by the outcropping Palaeozoic basement. On the western area, the effects of the complex geology of the Sardinian rift, with its volcanism (Pala et al., 1982), the Campidano graben and the smaller dimensions of the Palaeozoic blocks determine a more complex structure of the anomalies.

Filtering techniques have been used to separate the gravity effects of the deep structures from those of the upper ones. Two-dimensional ideal low-pass filters were applied in the wave number domain to Bouguer anomalies. The sampling rate for the calculation of the Fourier Transform coincides with that used in the in-

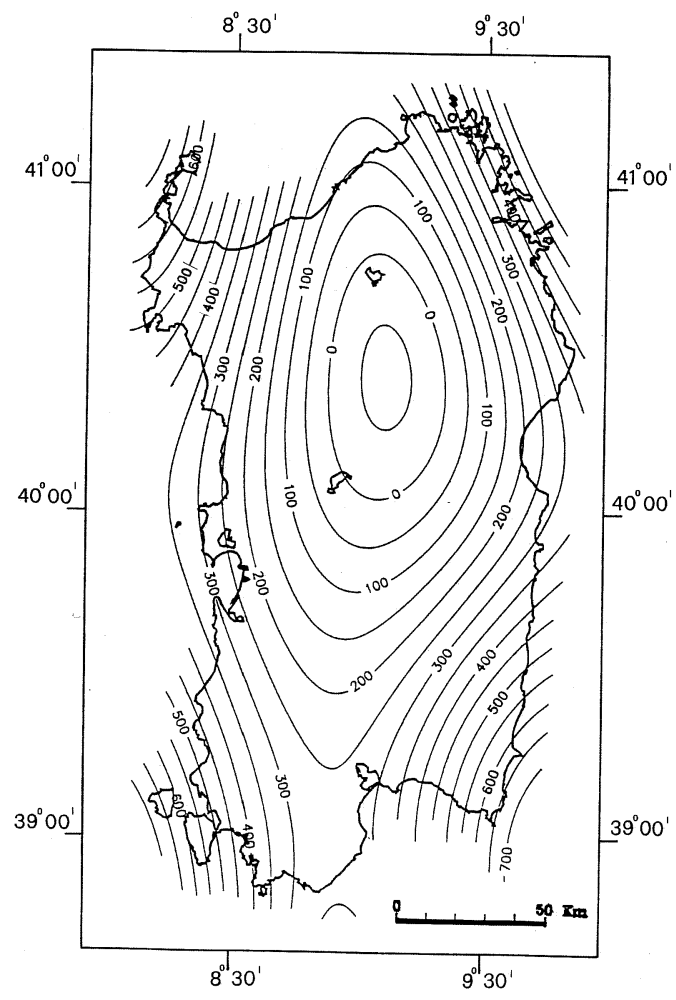

Fig. 6. Filtered gravity anomalies. The first harmonic $\left(\lambda_{\mathrm{EW}} \geq 171 \mathrm{~km}, \lambda_{\mathrm{NS}} \geq 305 \mathrm{~km}\right)$. Contour interval $50 \mathrm{gu}$. terpolation of the anomalies. Figure 6 shows the anomaly field obtained by selecting the first harmonic in either direction $\left(\lambda_{\mathrm{EW}} \geq 171 \mathrm{~km}\right.$, $\left.\lambda_{\mathrm{NS}} \geq 305 \mathrm{~km}\right)$. This map clearly defines a minimum $(-50 \mathrm{gu})$ which covers a large area: its longer axis extends in the N-S direction. By Fourier synthesis of the first two harmonics in each direction $\left(\lambda_{\mathrm{EW}} \geq 86 \mathrm{~km}, \lambda_{\mathrm{NS}} \geq 153 \mathrm{~km}\right)$ the filtered field shown in fig. 7 was obtained. Here a separation into two minimum areas can clearly be observed: one centred in the northern granitic area, the other in the south-western sector corresponding to the Campidano graben. Furthermore, the axis of the anomalies rotates from N-S to NW-SE, a direction which happens to be more closely related to the typical structural features of Sardinia. This behaviour

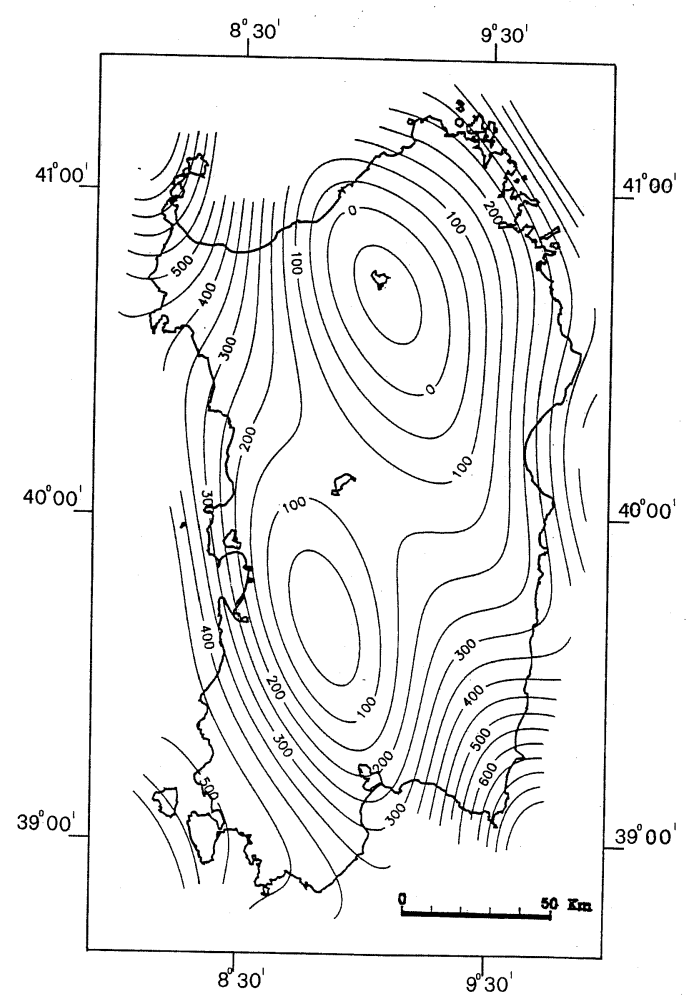

Fig. 7. Filtered gravity anomalies. The first two harmonics $\left(\lambda_{\mathrm{EW}} \geq 86 \mathrm{~km}, \lambda_{\mathrm{NS}} \geq 153 \mathrm{~km}\right)$. Contour interval $50 \mathrm{gu}$. 


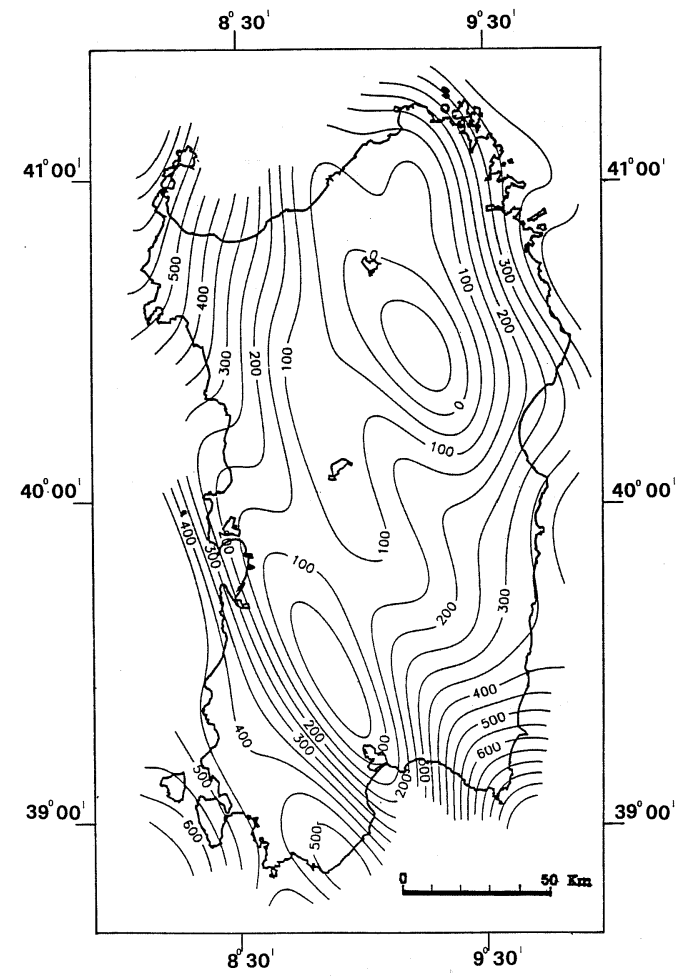

Fig. 8. Filtered gravity anomalies. The first four harmonic $\left(\lambda_{\mathrm{EW}} \geq 43 \mathrm{~km}, \lambda_{\mathrm{NS}} \geq 76 \mathrm{~km}\right)$. Contour interval $50 \mathrm{gu}$.

becomes more evident as the next harmonics are considered. Figure 8 shows the filtered field obtained by synthetizing the first four harmonics in each direction $\left(\lambda_{\mathrm{EW}} \geq 43 \mathrm{~km}\right.$, $\left.\lambda_{\mathrm{NS}} \geq 76 \mathrm{~km}\right)$.

\section{Gravity anomalies interpretation}

From the theory of inverse problems for potential field data it is well known that it is possible to estimate the mean depth of a discontinuity under the hypothesis that the distances of the points from it obey certain statistical laws. Spector and Grant (1970) first supplied a technique to estimate the mean depth of a magneticsusceptibility discontinuity surface, based on a statistical analysis of aeromagnetic anomalies performed in the wave number domain. The generalization of this spectral technique to Bouguer anomaly data analysis was proposed by several authors (Gerard and Debeglia, 1975; Mishra and Pedersen, 1982; Granser et al., 1989; Chakraborty and Agarwal, 1992). The application of such methods to experimental data, gravimetric or aeromagnetic, show that it is hard to estimate the changes in the spectral slope, related to the mean depths, when wave numbers different ranges are near and/or few points of the power spectrum are used

In an attempt of obtain information on the deep crustal structures of Sardinia not depending on seismic data, for a better integration of these two kinds of data, the power spectra relative to 10 profiles in the E-W direction and 2 in the N-S one (along the seismic profiles II and III of the European Geotraverse, Egger et al., 1988) were calculated and analyzed. The profiles along the E-W direction are located at a relative distance of $20 \mathrm{~km}$; the planimetric position of three of them is shown in fig. 4. Each profile is $160 \mathrm{~km}$ long, with a sampling rate of 1 datum per kilometre. Almost all the power spectra calculated are characterized by a steep negative slope in the lowest wave numbers followed by a second spectral peak. The low variance and a certain regularity of the variations of the negative slope estimates relative to these two spectrum portions suggest they could be associated to the depth of two deep interfaces present all over the area investigated, according to the known spectral law. In order to make the depth estimates statistically more significant, the same analysis was repeated re-sampling the profiles with a lower rate and shifting the window of sampling.

Figure 9 represents the Bouguer anomalies and the spectra regarding the three profiles shown in fig. 4. These profiles cross areas of the anomaly maps which can be associated with different structural conditions. The northernmost profile $\mathrm{A}-\mathrm{A}^{\prime}$ cuts across the gravimetric minimum of Gallura; the southernmost one, $\mathrm{C}-\mathrm{C}^{\prime}$, cuts the negative anomaly of Campidano and the central, B- $\mathrm{B}^{\prime}$, crosses the transitional areas situated between the two minima characterized by relatively weak gravimetric gradi- 


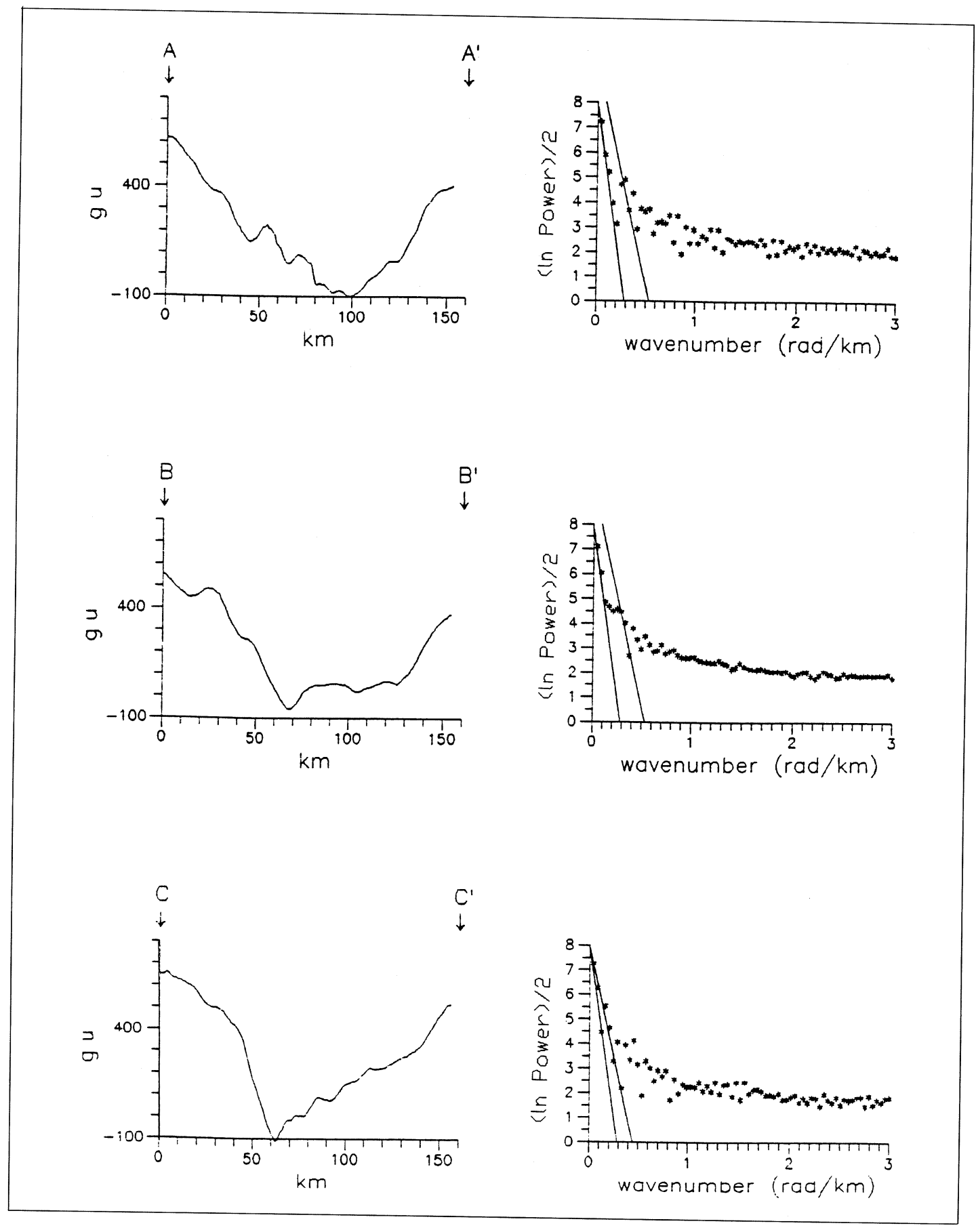

Fig. 9. Power spectra of the gravity anomalies along the three profiles shown in fig. 4 . 
ents. All the calculated spectra indicate with sufficient accuracy the presence of a discontinuity in the density distribution existing throughout the region, with a mean depth of $\sim 28 \mathrm{~km}$. The comprehensive analysis of the spectra relative to a great amount of data also showed that the second spectral slope, featured by a much greater variance, indicates the presence of another density discontinuity at a mean depth of $\sim 18 \mathrm{~km}$. Besides, the identification of the discontinuity at $18 \mathrm{~km}$ is more difficult to ascertain in those profiles located in the central area, where the gravimetric gradient is very low.

The data deduced from the analysis of the spectra let us assume in the first place a very simple crustal model, in which, above the Moho lying at a mean depth of $28 \mathrm{~km}$, there is only one infracrustal discontinuity at a mean depth of $18 \mathrm{~km}$. At such a depth it is reasonable to refer to this as the limit between the upper crust and the lower crust. A comparison between these results and the seismic models mentioned above shows a remarkable agreement with the models proposed by Egger et al. (1988). Also in this case the mean velocities of the layer between 18 and $28 \mathrm{~km}$, ranging between 6 and $7 \mathrm{~km} / \mathrm{s}$, suggest it is a lower crust.

In order to roughly reconstruct the shape of these two discontinuities, it was necessary to make some assumptions:

1) The shape of the Moho brings about gravitational effects mostly revealed by the first harmonic of the signal analyzed. This deduction is supported by some considerations:

a) the second harmonic has as its most outstanding effect to make visible the gravimetric effects of well known geological structures of the upper crust in the anomaly map;

$b)$ the analysis of the anomalies calculated for several models inferred that the characteristic wavelengths, in the surface effects originating from the density contrasts at a depth of 28 $\mathrm{km}$, are visibly greater than those of the second harmonic in the analyzed data.

2) Similar considerations also allowed us to assume that the trend of the infracrustal discontinuity has a major effect on the anomalies field up to the fourth harmonic, with a weak influence on all the others. This assumption is also confirmed by analysing the residual map
$\left(\lambda_{\mathrm{EW}}<43 \mathrm{~km}, \lambda_{\mathrm{NS}}<76 \mathrm{~km}\right)$ in fig. 10 , which is characterized by anomalies having small wavelengths.

3) Typical differences, ranging from 200 up to $300 \mathrm{~kg} / \mathrm{m}^{3}$, between the average density of the upper and lower crust in several zones of the Earth are reported in the scientific literature, inferred from seismic refraction profiles and high pressure laboratory measurements (Christensen and Mooney, 1995). Typical differences between the average density of the lower crust and the upper mantle, on the basis of similar data, may range from 300 up to $400 \mathrm{~kg} / \mathrm{m}^{3}$.

The gravimetric interpretation was carried out using bi-dimensional techniques along the A-A', B-B', C-C' profiles. According to what has been stated above, the Moho trend (fig. 11) was determined by interpreting the filtered

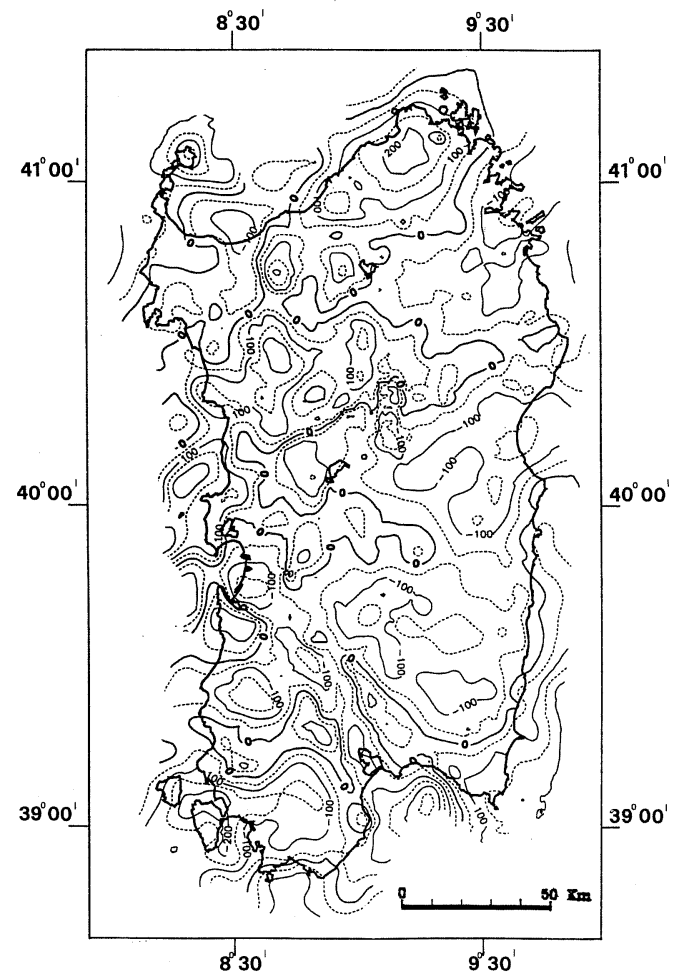

Fig. 10. Residual anomalies $\left(\lambda_{\mathrm{EW}}<43 \mathrm{~km}\right.$, $\left.\lambda_{\mathrm{NS}}<76 \mathrm{~km}\right)$. Contour interval $50 \mathrm{gu}$. 

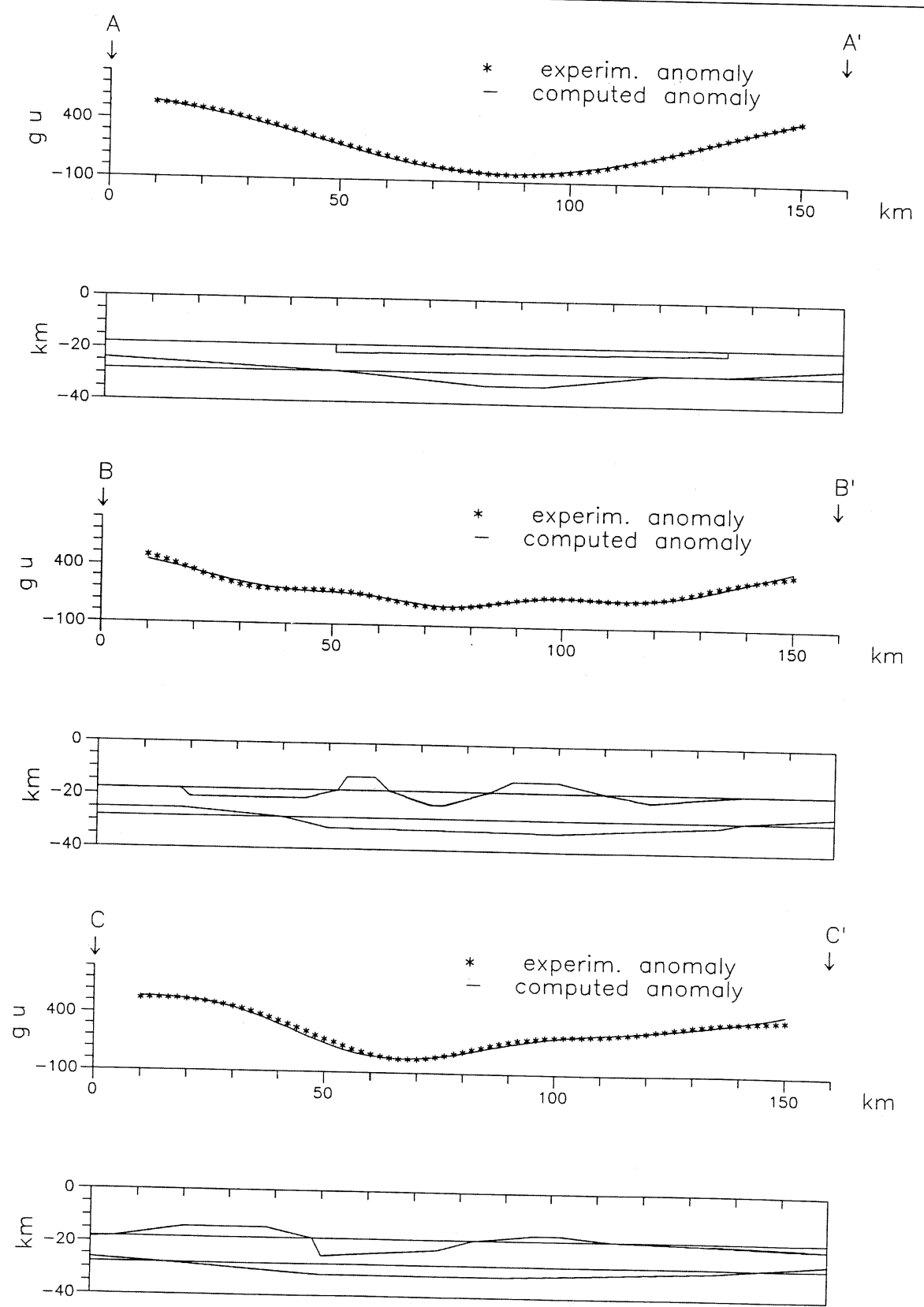

Fig. 11. Crustal models along the three profiles shown in fig. 4. Normal crust: mean depth of the Moho discontinuity $28 \mathrm{~km}$; mean depth of the infracrustal discontinuity $18 \mathrm{~km}$. Density contrast: lower crust-upper mantle $\Delta d=300 \mathrm{~kg} / \mathrm{m}^{3}$; upper crust-lower crust $\Delta d=250 \mathrm{~kg} / \mathrm{m}^{3}$. 


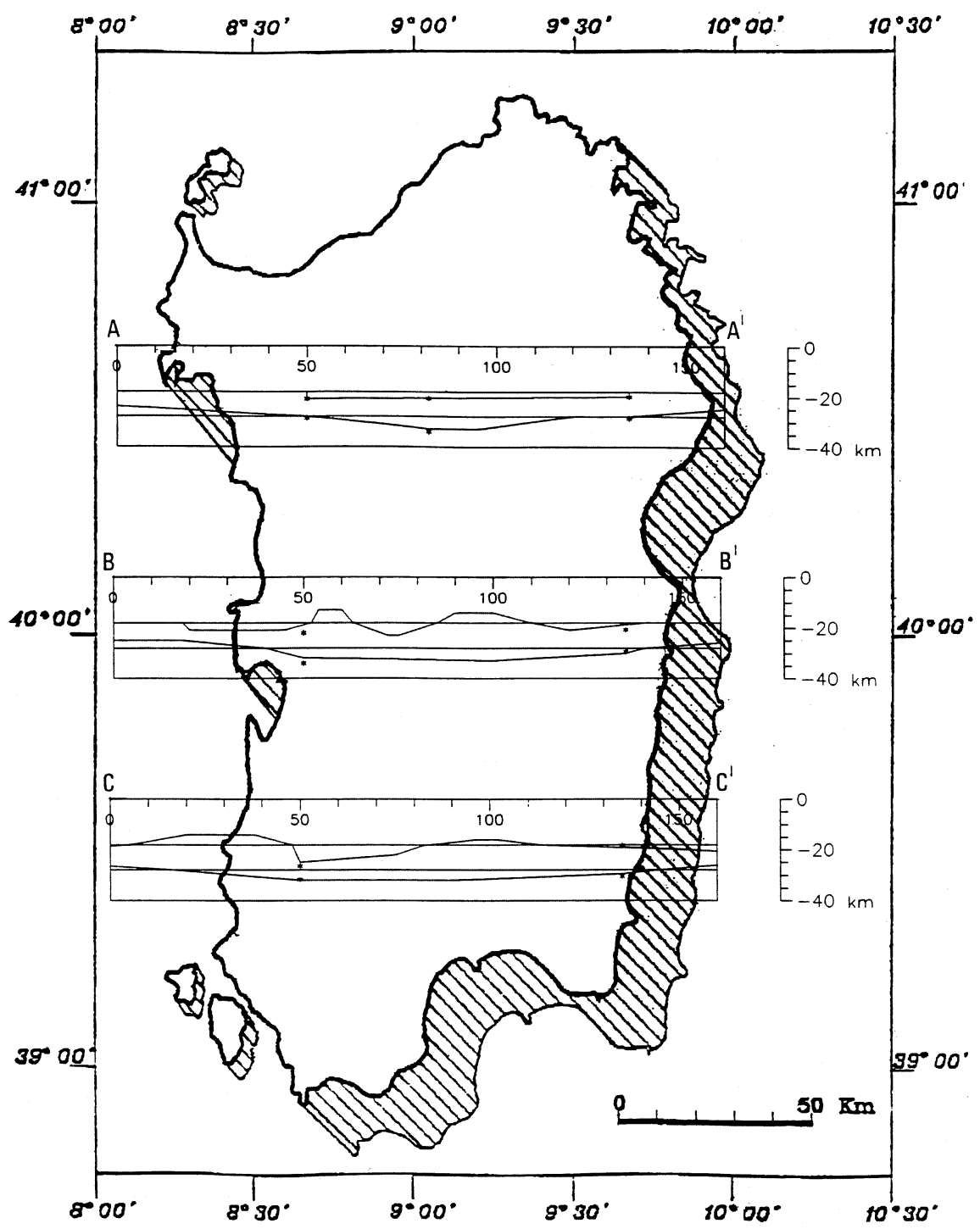

Fig. 12. Synthesis of gravity and seismic crustal models: $\sim$ gravity model; $*$ depth of seismic discontinuities at the intersection points between the geotraverse profiles and gravimetric ones.

anomalies corresponding to the first harmonic (fig. 6). On the other hand, for the trend of the infracrustal discontinuity (fig. 11) the Fourier synthesis was used up to the fourth harmonic of the filtered anomalies (fig. 8). The Talwani (Talwani et. al., 1959) method was used for the calculation of the gravimetric effects. Figure 11 shows the models obtained assuming the following values for the contrast of density: mantle-lower crust $300 \mathrm{~kg} / \mathrm{m}^{3}$, lower crust-upper crust $250 \mathrm{~kg} / \mathrm{m}^{3}$. In the northern profile $\mathrm{A}-\mathrm{A}^{\prime}$ the Moho reaches its maximum depth, 
which is of the order of $33 \mathrm{~km}$. The trend of the infracrustal discontinuity is more interesting for its possible correlation with the existing geology. The lowering discontinuity in the profile $\mathrm{A}-\mathrm{A}^{\prime}$ corresponds to the granitic massif. In the southern profiles $\mathrm{C}-\mathrm{C}^{\prime}$, the wide minimum on the western side (maximum depth $25 \mathrm{~km}$ ) corresponds to the Campidano graben.

Figure 12 shows the synthesis of the gravimetric models together with the position of the principal discontinuities singled out by the seismic method which allowed us to compare the results obtained by gravimetric interpretation with the seismic ones (Egger et al., 1988). As can be seen, at the intersection between the gravity and seismic profiles, the depth of the discontinuities obtained using the two techniques are in good agreement. A thinning of the supposed lower crust is particularly evident in the $\mathrm{C}-\mathrm{C}^{\prime}$ gravity profile (fig. 12). This clearly corresponds to the complete disappearance of the layer characterized by a $6.8 \mathrm{~km} / \mathrm{s}$ velocity in the crustal model corresponding to Profile II of the European Geotraverse (Egger et al., 1988, fig. 17). Finally, the gravity interpretation allows us to point out, in the central part of the island (profile B-B' and $C-\mathrm{C}^{\prime}$ ), a rather undulating shape of the infracrustal discontinuity with marked thickness variations of the lower crust. This cannot be deduced from the seismic profiles because of their position and the lower horizontal resolving power of the DSS method. On the other hand, these marked variations could also be due to the presence in the interpreted anomalies of effects produced by geological structures shallower than the discontinuity investigated.

\section{Conclusions}

As stated above, the gravimetric interpretation carried out in this phase of the project is self-consistent. It took place without the help of external constraints which come from the application of other geophysical methods. The proposed model showing the general characteristics of the crust confirms, among the velocity models obtained by different authors, that pro- posed by Egger et al. (1988). At this stage an integrated inversion of seismic and gravimetric data can be performed. In it the gravimetric information plays a decisive role in the choice of the main characteristics of the model, and, because of the high density of experimental data throughout the territory, the model resolution and reliability can also be improved for the shallowest structures.

\section{Acknowledgements}

This work was carried out with financial support from the Italian National Research Council (CNR) and from the Ministry for the University and Scientific and Technological Research (MURST).

\section{REFERENCES}

Balia, R., M.T. Carrozzo, A. Chirenti, M. Loddo, D. Luzio, C. Margiotta, T. Quarta, R. Trudu and F. ZuANNI (1983): Carta gravimetrica della Sardegna., in Atti II Convegno Annuale GNGTS, CNR, Roma, 61-471.

Balia, R., M. Ciminale, M. Loddo, G. Pecorini, G. RuiNA and R. TRUDU (1984): Gravity survey and interpretation of Bouguer anomalies in the Campidano geothermal area (Sardinia, Italy), Geothermics, 13, 333-347.

Balia, R., M. Ciminale, M. Loddo, D. Patella, G. PECORINI and A. TRAMACERE (1990): Geophysical study of the Fordongianus geothermal area (Sardinia Island, Italy), Boll. Geofis Teor. Appl., 32, 129-140.

Balia, R., M. Ciminale, M. Loddo, D. Patella, G. Pecorini and A. Tramacere (1991): A new geophysical contribution to the study of the Campidano geothermal area (Sardinia, Italy), Geothermics, 20, 147-163.

Biella, G., G. Gaudiosi, I. Guerra, G. LuOGo, M. MaISTRELLO and S. SCARASCIA (1983): Profili sismici profondi in Sardegna-1982, in Atti II Convegno Annuale GNGTS, CNR, Roma, 127-139.

BIRCH, F. (1964): Density and composition of mantle and core, J. Geophys. Res., 69, 4377-4388.

Carrozzo, M.T., A. Chirenti A, D. Luzio, C. MarGIOTTA and T. QuARTA (1981): Carta Gravimetrica d'Italia: tecniche automatiche per la sua realizzazione in Atti I Convegno Annuale GNGTS, CNR, Roma, 132-139.

Carrozzo, M.T., A. Chirenti, D. Luzio, C. Margiotta, T. Quarta, M. Tundo and F. ZuAnni (1985): Data base of mean height values for the whole Italian landmass and surrounding areas: determining and statistical analysis, Boll. Geod. Sci. Affini, 44 (1), 37-56. 
Chakraborty, K. and B.N.P. Agarwal (1992): Mapping of crustal discontinuities by wavelength filtering of the gravity field, Geophys. Prospect., 40, 801-822.

CHRISTENSEN, N.I. and W.D. MOONEY (1995): Seismic velocity structure and composition of the continental crust: a global view, J. Geophys. Res., 100 (B7), 97619788.

Egger, A., M. Demartin, J. Ansorge, E. Banda and M. MAISTRIELlo (1988): The gross structure of the crust under Corsica and Sardinia, Tectonophysics, 150, 363-389.

Gerard, A. and N. Debeglia (1975): Automatic three-dimensional modeling for the interpretation of gravity or magnetic anomalies, Geophysics, 40 (6), 1014-1054.

Granser, H., B. Meurers and P. Steinhauser (1989): Apparent resistivity mapping and 3D gravity inversion in the eastern Alps, Geophys. Prospect., 37, 279-292.

Guerra, I., the GrupPo ItAliano DEI GRANDI PROFILI SismicI (1981): Struttura crostale della Sardegna sulla base di dati sismici e gravimetrici, in Atti I Convegno Annuale GNGTS, CNR, Roma, 639-652.

MARSON, I. and C. MoRELLI (1978): First order gravity net in Italy, Paper Presented at the 8th Meeting of the International Gravity Commission, Paris 12-16 September 1978 .

MishrA, D.C. and L.B. PEDERSEN (1982): Statistical analysis of potential fields from subsurface reliefs, Geoexploration, 19, 247-265.

Morelli, C., C. Gantar, T. Honkasalo, P.K. MCConnell, I.G. Tanner, B. Szabo, U. Uotila and C.T. WHALEN (1974): The international gravity standardization net 1971 (IGSN 71), Int. Ass. of Geodesy, Spec. Publ., IUGG, No. 4, pp. 194.
NAFE, J.E and C.L. DRAKE (1957): Variation with depth in shallow and deep water marine sediments of porosity, density and the velocities of compressional and shear waves, Geophysics, 22, 523-552.

Pala, A., G. Pecorini, A. Porcu and S. Serra (1982): Schema geologico strutturale della Sardegna, Consiglio Nazionale delle Ricerche (CNR), P.F.E. RF 10, 7-24.

Pecorini, G., R. Balia, M. Ciminale, M. Loddo, D. Patella and A. Tramacere (1988): Studio geofisico del bacino del Logudoro (Sardegna) e delle aree circostanti, Boll. Soc. Geol. It., 107, 547-560.

SAlvadori, I., I. URAS and P. ZuFFARdi (1986): The Palaeozoic metallogenesis of Sardinia in relation to its geological evolution, in Guide-Book to the Excursion on the Palaeozoic Basement of Sardinia, IGCP project No. 5 - Newsletter 1986, special issue, 23-25.

Spector, A. and F.S. Grant (1970): Statistical models for interpreting aeromagnetic data, Geophysics, 35 (2), 293-302.

TAlWANI, M., L. WORZEL and M. LANDISMAN (1959): Rapid gravity computation for two-dimensional bodies with application to Mendocino submarine fracture zone, J. Geophys. Res., 64, 49-59.

TRUdU, R. (1962): Rilevamento gravimetrico della Sardegna, Boll. Geofis Teor. Appl., 4, 299-339.

Trudu, R. (1963): Prime considerazioni sul rilevamento gravimetrico della Sardegna, Resoconti Assoc. Min. Sarda, 67 (5), 5-23.

VeCCHIA, O. (1955): Carta della densità media sino al livello del mare in Italia, ser. V, No. 9, Milano. 